\title{
Peripheral levels of selected adipokines in patients with newly diagnosed multiple sclerosis
}

\author{
Agnieszka Baranowska-Bik1, Dorota Uchman², Anna Litwiniuk³, Małgorzata Kalisz ${ }^{3}$, Lidia Martyńska ${ }^{3}$, \\ Bogusława Baranowska², Wojciech Bik', Jan Kochanowski
}

${ }^{1}$ Department of Endocrinology, Centre of Postgraduate Medical Education, Bielański Hospital, Warsaw, Poland

${ }^{2}$ Department of Neurology, Faculty of Medicine, Medical University of Warsaw, Bielański Hospital, Warsaw, Poland

${ }^{3}$ Department of Neuroendocrinology, Centre of Postgraduate Medical Education, Warsaw, Poland

\begin{abstract}
Introduction: Multiple sclerosis (MS) is an autoimmune disease of the central nervous system. The exact aetiology is unknown. However, genetic and environmental factors are suggested to be involved in the pathogenesis of MS. Improper diet, resulting in obesity and metabolic syndrome, can contribute to this disease. Adipokines, secreted by adipose tissue, link the metabolism and immune system.

Material and methods: We aimed to assess plasma levels of selected adipokines in newly diagnosed, treatment-naïve individuals with multiple sclerosis. Our group comprised 58 individuals (31 MS patients and 27 controls, matched for age and BMI) without diabetes, hypertension, or dyslipidaemia. Circulating adiponectin and all adiponectin fractions, visfatin, and omentin concentrations were measured. Metabolic parameters were also assessed.

Results: In MS individuals we observed the following results: higher concentrations of visfatin, lower levels of omentin, and no differences in adiponectin array. There were also correlations between some adipokines and metabolic parameters. After adjustment to BMI, a significant decrease in total adiponectin, high-molecular weight (HMW) adiponectin and omentin, and an increase in medium-molecular-weight (MMW) adiponectin were observed in the group of MS patients when compared to those of the controls.

Conclusions: Our results indicate that adiponectin with its fractions, visfatin, and omentin cannot be considered as causative factors in the early phase of multiple sclerosis. However, the potential role of adipokines in MS is possible because they might be involved in the pathogenesis of MS, regarded as an autoimmune disorder. (Endokrynol Pol 2020; 71 (2): 109-115)
\end{abstract}

Key words: adiponectin; adiponectin fractions; visfatin; omentin; multiple sclerosis

\section{Introduction}

Multiple sclerosis (MS) is a chronic disease of the central nervous system, which leads to disability. It affects over 400,000 Americans and approximately 2.3 million people worldwide [1]. Although the exact mechanisms leading to MS are not fully understood, it is widely accepted that this disease belongs to a family of autoimmune disorders [2]. Data from studies concerning the causes and course of this illness indicate that a disturbed immune system plays a causative role in the pathomechanism of MS [3]. The interaction between genetic predisposition and environmental factors is also necessary to initiate the disease [4]. Amongst the environmental factors, improper diet and obesity have been closely associated with MS [5]. According to the current knowledge, adipose tissue, comprised adipocytes and immune-competent cells, can produce and secrete biologically active substances, adipokines, and cytokines. Impaired adipose tissue function that is seen in obesity results in altered adipokine and cytokine profile. Consequently, disturbed adipokine and cytokine secretion leads to chronic low-grade inflammation. Adipokines link the metabolism and the immune system [6].

Adiponectin is a hormone derived mainly from the adipose tissue. It is worth noticing that adiponectin is downregulated in obesity [7] and is inversely correlated with BMI (body mass index), which serves as the simplest repeatable indicator of adipose tissue amount. Decreased adiponectin levels may have an impact on the pathogenesis of insulin resistance; a negative correlation between adiponectin and insulin resistance index, HOMA-IR, was observed in subject with prediabetes [8].

Adiponectin has anti-inflammatory, anti-atherogenic, and insulin-sensitising properties [9]. This adipokine exerts its action through three receptors AdipoR1, AdipoR2, and T-cadherin [10]. Adiponectin circulates in three main forms depending on its post-translational modification: low-molecular-weight (LMW) trimers, medium-molecular-weight (MMW) hexamers, and 
high-molecular-weight (HMW) multimers [11]. The biological activity differs between the forms. HMW adiponectin is believed to possess more potent biological effects than other fractions, especially on metabolic homeostasis, whereas LMW is associated with autoimmune processes [12,13]. It has been found that adiponectin may influence the immunological system. Adiponectin possesses anti-inflammatory activity [14] - the following mechanisms of adiponectin action on immune cells have been reported: suppression of the proliferation of myelomonocytic precursor cells and the phagocytic activity of mature macrophages [15], regulation of tumour necrosis factor alpha (TNF $\alpha)$ and interferon gamma (IFN $\gamma$ ) production in response to antigen presentation [16], and the induction of interleukin 10 (IL-10) and 1 (IL-1) receptor antigen (IL-1RA) in monocytes, macrophages, and dendritic cells (DC) [3, 6]. Furthermore, adiponectin acts on endothelial cells by inhibiting the expression of TNF $\alpha$-induced adhesion molecules, such as vascular cell adhesion molecule 1 (VCAM-1), endothelial-leukocyte adhesion molecule 1 (E-selectin), and intracellular adhesion molecule 1 (ICAM-1). The result of this particular adiponectin activity includes reduced monocyte adhesion to endothelial cells $[6,14]$.

Interestingly, in human monocytic cells, HMW adiponectin has been shown to induce IL-6 production and secretion, while LMW acted as an anti-inflammatory factor because it reduced the production of IL-6 and inhibition of IL-10 synthesis [17]. Therefore, adiponectin, dependent on the isoform, may have pro- or anti-inflammatory activity. Furthermore, adiponectin release could be modulated during inflammation because TNF $\alpha$ impairs adiponectin multimerisation and decreases its secretion [18].

Visfatin, named also pre-B-cell colony-enhancing factor, is predominantly secreted by macrophages of visceral adipose tissue. Visfatin is induced by peroxisome proliferator-activated receptor gamma in macrophages, mostly M1 subtype localised in adipose tissue, but not in adipocytes $[19,20]$. The level of visfatin increases significantly in obesity [21]. It acts as a potent modulator of inflammation with dual pro- and anti-inflammatory activity. Visfatin may upregulate the secretion of TNF $\alpha$, IL-1 $\beta$, and IL- 6 as well as IL-4, IL-10, and IL-1Ra [20]. It promotes activation of T cells by enhancing the expression of co-stimulatory molecules, including CD40, CD54, and CD80, on monocytes [6]. Visfatin acts as a chemotactic factor on monocytes and lymphocytes. Visfatin possesses also the ability to increase levels of selected cell adhesion molecules ICAM-1, VCAM-1, and E-selectin in endothelial cells [22]. Also, visfatin affects the development of $B$ and $T$ cells [22]. Omentin is predominantly produced by the stromal-vascular fraction of visceral adipose tissue, but not by mature adipocytes. Interestingly, only very small amounts of omentin are produced by subcutaneous adipose tissue [23]. Production of omentin remains under glucose and insulin regulation [24]. It has been suggested that omentin plays a role in metabolic diseases, bone metabolism, inflammatory diseases, and others. Moreover, an association between decreased omentin levels and these diseases has been observed. However, enhanced omentin concentration was related to the acute phase after the onset of these diseases [25].

In reference to existing data concerning the potential role of adipokines in inflammatory processes and our experience in assessment of adipokines in Alzheimer's disease, a disease caused both by neurodegeneration and local inflammation [26], we aimed to assess the levels of selected adipokines in newly diagnosed, naïve-to-treatment patients with multiple sclerosis. Also, in our study sample, some individuals presented overweight or obesity but no other metabolic abnormalities (needed to treat dyslipidaemia, diabetes mellitus, hypertension).

\section{Material and methods}

\section{Subjects}

The study included 31 individuals (21 women and 10 men) with newly diagnosed multiple sclerosis, aged between 19 and 48 years (median: 33 years), and 27 subjects ( 23 women and four men) from the control group, aged between 27 and 40 years (median: 33 years). The controls were recruited from patients with tension headaches. The whole group under the study was hospitalised once in a single centre, the Department of Neurology of the Medical University of Warsaw (Bielanski Hospital Warsaw, Poland).

All study participants underwent the same diagnostic procedures: medical examination, brain magnetic resonance imaging (MRI) scan with gadolinium contrast, and cerebrospinal fluid examination performed to confirm or exclude the presence of oligoclonal bands and to determine the cerebrospinal (CSF) immunoglobulin (IgG) index. Diagnosis of MS was established according to the Diagnostic Criteria for Multiple Sclerosis (2010 Revisions to the "McDonald Criteria") [27]. The severity of neurological symptoms of MS was evaluated using the Expanded Disability Status Scale (EDSS). Based on the medical history and records, the time from the first symptoms of MS to the disease diagnosis was from one to six months. At the time of hospitalisation, all MS patients had clinical manifestations of the disease (with disease relapse). MS individuals were naïve to any MS treatment.

To avoid potential confounding factors in adipokine assessment, we carefully selected study participants and excluded all subjects with diabetes mellitus, hypertension, and dyslipidaemia as well as those treated with anti-hypertensive, anti-diabetic, and cholesterollowering medications. Exclusion criteria included also heart failure, liver and kidney failure, active cancer, or history of cancer disease, diabetes insipidus, mental illness, endocrine disorders, and any type of corticosteroid treatment within the last three months. Smokers and alcohol drinkers were not selected to participate in the study. The study protocol was accepted by the Ethical Commission of the Centre of Postgraduate Medical Education, Warsaw. The study was conducted in accordance with the principles of the Helsinki II Declaration. Signed consent was obtained from all participants. 


\section{Anthropometric measurements}

Anthropometric measurements were carried out in each patient to assess the body mass index (BMI). BMI was calculated according to the standard formula: weight / height $\left[\mathrm{kg} / \mathrm{m}^{2}\right]$.

\section{Analytical methods}

Blood samples were taken after at least six hours of fasting. Blood was collected in tubes containing EDTA. The plasma was separated by centrifuged at $1200 \mathrm{~g}$ for 10 minutes at $4^{\circ} \mathrm{C}$ and immediately stored at $-70^{\circ} \mathrm{C}$ until further peptide analyses. Biochemical parameters, including fasting plasma glucose levels, and lipid profiles were estimated using routine laboratory tests. Insulin resistance was calculated from the fasting plasma insulin and glucose values using the homeostasis model assessment of insulin resistance (HOMA-IR) formula:

fasting plasma glucose $[\mathrm{mmol} / \mathrm{L}] \times$ fasting plasma insulin concentration $[\mu \mathrm{IU} / \mathrm{mL}] / 22.5$

Insulin resistance was defined as HOMA-IR > 2.5.

\section{Hormone assays}

Plasma total adiponectin and HMW, MMW, and LMW adiponectin concentrations were measured using a commercial enzyme-linked immunosorbent assay kit (ELISA) according to the manufacturer's protocol (ALPCO Diagnostics, Windham, NH, USA). The sensitivity of the assay was $0.019 \mathrm{ng} / \mathrm{mL}$. The intra-assay coefficient of variation (CV) was 5.4\% for total adiponectin, 5.0\% for HMW adiponectin and MMW + HMW adiponectin, while the inter-assay CV was $5.0 \%$ for total adiponectin, 5.7\% for HMW adiponectin, and 6.0\% for MMW + HMW adiponectin.

Plasma omentin concentration was measured by ELISA kit according to the manufacturer's protocol (BioVendor Laboratory Medicine, Brno, Czech Republic). The sensitivity of the assay was $0.5 \mathrm{ng} / \mathrm{mL}$. The intra-assay and inter-assay CV were less than $5 \%$. Plasma visfatin concentration was measured by an enzyme immunoassay kit (EIA) according to the manufacturer's protocol (Phoenix Pharmaceuticals Inc., Burlingame, CA, USA). The sensitivity value for visfatin was $2.68 \mathrm{ng} / \mathrm{mL}$. The intra-assay and inter-assay $\mathrm{CV}$ were less than $10 \%$ and $15 \%$, respectively.

Plasma insulin concentrations were determined using immunoradiometric assay (DIA Source Immunoassay SA, Nivelles, Belgium). The detection limit was $1 \mu \mathrm{IU} / \mathrm{mL}$. Intra- and inter-assay coefficients of variation were $2.1 \%$ and $6.5 \%$, respectively.

\section{Statistical analysis}

Statistical analysis was conducted using Statistica 12 (StatSoft Inc., USA). Data are given as median and interquartile range (IQ range). The normality of distribution was estimated using the Shapiro-Wilk test. Results were compared between MS and control groups by Mann-Whitney U test. The coefficient correlation between tested adipokines and anthropometric as well as metabolic parameters was applied with the use of the Spearman test. All adipokines were adjusted to BMI. The values $<0.05$ were considered as statistically significant.

\section{Results}

Clinical and anthropometric data, as well as biochemical results of patients diagnosed with multiple sclerosis and the control group, are presented in Table 1.

There were no statistically significant differences between the examined groups in terms of age, BMI, total cholesterol, HDL-cholesterol, LDL-cholesterol, and triglycerides. In the group of patients with MS, significantly higher insulin values were found (medians:
Table 1. Patients' demographic and clinical parameters

\begin{tabular}{|c|c|c|c|}
\hline & $\begin{array}{l}\text { MS group } \\
(\mathrm{n}=\mathbf{3 1})\end{array}$ & $\begin{array}{l}\text { Control group } \\
(n=27)\end{array}$ & p \\
\hline Age (years) & $\begin{array}{c}33 \\
(29-39)\end{array}$ & $\begin{array}{c}33 \\
(27-40)\end{array}$ & NS \\
\hline $\mathrm{BMI}\left[\mathrm{kg} / \mathrm{m}^{2}\right]$ & $\begin{array}{c}22.8 \\
(20.9-26.2)\end{array}$ & $\begin{array}{c}24.46 \\
(21.97-27.14)\end{array}$ & NS \\
\hline EDSS & $\begin{array}{c}1.5 \\
(1-2)\end{array}$ & - & - \\
\hline $\begin{array}{l}\text { Total cholesterol } \\
{[\mathrm{mg} / \mathrm{dL}]}\end{array}$ & $\begin{array}{c}182.5 \\
(163.3-205.1)\end{array}$ & $\begin{array}{c}177.23 \\
(152-199.8)\end{array}$ & NS \\
\hline $\begin{array}{l}\text { HDL-cholesterol } \\
{[\mathrm{mg} / \mathrm{dL}]}\end{array}$ & $\begin{array}{c}62.5 \\
(46.3-74.5)\end{array}$ & $\begin{array}{c}55.00 \\
(45.9-71.2)\end{array}$ & NS \\
\hline $\begin{array}{l}\text { LDL-cholesterol } \\
{[\mathrm{mg} / \mathrm{dL}]}\end{array}$ & $\begin{array}{c}103.4 \\
(81.7-126)\end{array}$ & $\begin{array}{c}99.8 \\
(76.80-121.7)\end{array}$ & NS \\
\hline $\begin{array}{l}\text { Triglycerides } \\
{[\mathrm{mg} / \mathrm{dL}]}\end{array}$ & $\begin{array}{c}77.9 \\
(56.4-120)\end{array}$ & $\begin{array}{c}88.76 \\
(57.7-125.9)\end{array}$ & NS \\
\hline $\begin{array}{l}\text { Glucose } \\
{[\mathrm{mg} / \mathrm{dL}]}\end{array}$ & $\begin{array}{c}90.0 \\
(83.6-97)\end{array}$ & $\begin{array}{c}92.8 \\
(85.3-99.0)\end{array}$ & NS \\
\hline Insulin $[\mu \mathrm{IU} / \mathrm{mL}]$ & $\begin{array}{c}14 \\
(9.8-23.5)\end{array}$ & $\begin{array}{c}9 \\
(8.4-12.5)\end{array}$ & $<0.05$ \\
\hline HOMA-IR & $\begin{array}{c}3.27 \\
(2.12-5.28)\end{array}$ & $\begin{array}{c}2.16 \\
(1.8-3.7)\end{array}$ & 0.08 \\
\hline
\end{tabular}

Data are given as a median and interquartile range (I0 range). MS — multiple sclerosis; BMI — body mass index; EDSS — Expanded Disability Status Scale; HDL — high-density lipoproteins; LDL — low-density lipoproteins; HOMA-IR - Homeostatic Model Assessment-Insulin Resistance; NS - non-significant

$14 \mu \mathrm{IU} / \mathrm{mL}$ vs. $9 \mu \mathrm{IU} / \mathrm{mL} ; \mathrm{p}<0.05)$, while HOMA-IR showed a tendency for higher values (medians: 3.27 vs. 2.16; $\mathrm{p}=0.08)$.

The analysis showed an increased concentration of visfatin and decreased values of omentin in patients with newly diagnosed MS in comparison to the results of the controls (medians: $9.64 \mathrm{ng} / \mathrm{mL}$ vs. $8.76 \mathrm{ng} / \mathrm{mL}$; $\mathrm{p}<0.05$ and $240.91 \mathrm{ng} / \mathrm{mL}$ vs. $313.59 \mathrm{ng} / \mathrm{mL} ; \mathrm{p}<0.05$, respectively). There were no significant differences between the studied groups when adiponectin and all its fraction concentrations were compared.

To exclude the influence of adiposity, measured with BMI, in the evaluation of the adipokines, we adjusted the adipokine levels to BMI. After adjustment, a statistically significant decrease in total adiponectin (medians: $4.5 \mu \mathrm{g} / \mathrm{mL}$ vs. $5.65 \mu \mathrm{g} / \mathrm{mL}$; $\mathrm{p}<0.001$ ), HMW adiponectin (medians: $2.4 \mu \mathrm{g} / \mathrm{mL}$ vs. $2.74 \mu \mathrm{g} / \mathrm{mL}$; $\mathrm{p}<0.001$ ), as well as omentin (medians: $240.91 \mathrm{ng} / \mathrm{mL}$ vs. $313.59 \mathrm{ng} / \mathrm{mL} ; \mathrm{p}<0.05$ ) and an increase in MMW adiponectin (medians: $1.22 \mu \mathrm{g} / \mathrm{mL}$ vs. $1.03 \mu \mathrm{g} / \mathrm{mL}$; $\mathrm{p}<0.001$ ) were observed in the group of MS patients when compared to those of the controls. There were no significant differences in LMW levels of adiponectin before and after adjustment to BMI. Moreover, after adjustment to BMI, differences in visfatin levels became non-significant. 
Table 2. Assessment of adipokines in patients with multiple sclerosis (MS) and the controls

\begin{tabular}{|c|c|c|c|c|}
\hline & $\begin{array}{l}\text { MS group } \\
(\mathbf{n}=\mathbf{3 1})\end{array}$ & $\begin{array}{l}\text { Control group } \\
(\mathrm{n}=27)\end{array}$ & $\mathbf{p}$ & p adjusted to BMI \\
\hline Total adiponectin [ug/mL] & $\begin{array}{c}4.5 \\
(2.9-7.6)\end{array}$ & $\begin{array}{c}5.65 \\
(4.3-6.1)\end{array}$ & NS & $<0.001$ \\
\hline HMW adiponectin [ug/mL] & $\begin{array}{c}2.4 \\
(1.2-3.5)\end{array}$ & $\begin{array}{c}2.74 \\
(2.0-3.5)\end{array}$ & NS & $<0.001$ \\
\hline MMW adiponectin [ug/mL] & $\begin{array}{c}1.22 \\
(0.8-1.9)\end{array}$ & $\begin{array}{c}1.03 \\
(0.6-1.6)\end{array}$ & NS & $<0.001$ \\
\hline LMW adiponectin [ug/mL] & $\begin{array}{c}1.15 \\
(0.7-1.7)\end{array}$ & $\begin{array}{c}1.41 \\
(1.2-1.8)\end{array}$ & NS & NS \\
\hline Visfatin [ng/mL] & $\begin{array}{c}9.64 \\
(7.8-12.0)\end{array}$ & $\begin{array}{c}8.76 \\
(5.3-10.3)\end{array}$ & $<0.05$ & NS \\
\hline Omentin $[\mathrm{ng} / \mathrm{mL}]$ & $\begin{array}{c}240.91 \\
(152-381)\end{array}$ & $\begin{array}{c}313.59 \\
(263-434)\end{array}$ & $<0.05$ & $<0.05$ \\
\hline
\end{tabular}

Data are given as a median and interquartile range (IO range). MS — multiple sclerosis; HMW — high molecular weight; MMW — medium molecular weight; LMW — low molecular weight; BMI — body mass index; NS — non-significant

Table 3. Correlations of adiponectin and its fractions in patients with multiple sclerosis (MS)

\begin{tabular}{lccc}
\hline Parameter A & Parameter B & $\mathbf{R}$ & $\mathbf{p}$ \\
\hline Total adiponectin & BMI & -0.60 & $<0.001$ \\
\hline Total adiponectin & HDL-cholesterol & 0.64 & $<0.001$ \\
\hline Total adiponectin & LDL-cholesterol & -0.42 & $<0.05$ \\
\hline Total adiponectin & Insulin & -0.48 & $<0.01$ \\
\hline Total adiponectin & HOMA-IR & -0.47 & $<0.01$ \\
\hline HMW adiponectin & BMI & -0.53 & $<0.001$ \\
\hline HMW adiponectin & HDL-cholesterol & 0.61 & $<0.001$ \\
\hline HMW adiponectin & LDL-cholesterol & -0.40 & $<0.05$ \\
\hline HMW adiponectin & Insulin & -0.54 & $<0.01$ \\
\hline HMW adiponectin & HOMA-IR & -0.53 & $<0.001$ \\
\hline MMW adiponectin & BMI & -0.58 & $<0.001$ \\
\hline MMW adiponectin & HDL-cholesterol & 0.55 & $<0.01$ \\
\hline MMW adiponectin & Triglycerides & -0.40 & $<0.05$ \\
\hline LMW adiponectin & BMI & -0.36 & $<0.05$ \\
\hline LMW adiponectin & HDL-cholesterol & 0.45 & $<0.05$ \\
\hline LMW adiponectin & LDL-cholesterol & -0.41 & $<0.05$ \\
\hline HMW - & &
\end{tabular}

HMW — high molecular weight; MMW — medium molecular weight;

LMW — low molecular weight; BMI — body mass index; HDL — high-density lipoproteins; LDL — low-density lipoproteins; HOMA-IR — Homeostatic Model Assessment-Insulin Resistance

Data concerning adipokines are presented in Table 2.

Correlations of adiponectin and its fractions with other parameters are presented in Table 3.

In detail, as could be expected, positive correlations of total adiponectin and HMW adiponectin with HDL-cholesterol ( $\mathrm{R}=0.64 ; \mathrm{p}<0.001$ and $\mathrm{R}=0.61 ; \mathrm{p}<0.001$, respectively) and negative with BMI $(\mathrm{R}=-0.60 ; \mathrm{p}<0.001$ and $\mathrm{R}=-0.53 ; \mathrm{p}<0.001$,
Table 4. Correlations of omentin in patients with multiple sclerosis (MS)

\begin{tabular}{lccc}
\hline Parameter A & Parameter B & R & p \\
\hline Omentin & Insulin & -0.47 & $<0.01$ \\
\hline Omentin & HOMA-IR & -0.43 & $<0.05$ \\
\hline
\end{tabular}

HOMA-IR — Homeostatic Model Assessment-Insulin Resistance

respectively) LDL-cholesterol $(\mathrm{R}=-0.42 ; \mathrm{p}<0.05$ and $\mathrm{R}=-0.40 ; \mathrm{p}<0.05$, respectively), insulin $(\mathrm{R}=-0.48$; $\mathrm{p}<0.01$ and $\mathrm{R}=-0.54 ; \mathrm{p}<0.01$, respectively), and HOMA-IR $(\mathrm{R}=-0.47 ; \mathrm{p}<0.01$ and $\mathrm{R}=-0.53 ; \mathrm{p}<0.001$, respectively) were found. Medium molecular-weight adiponectin correlated positively with HDL-cholesterol $(\mathrm{R}=0.55 ; \mathrm{p}<0.01)$ and negatively with $\mathrm{BMI}(\mathrm{R}=-0.58$; $\mathrm{p}<0.001)$ and triglycerides $(\mathrm{R}=-0.40 ; \mathrm{p}<0.05)$. Low molecular-weight adiponectin showed negative correlations with $\mathrm{BMI}(\mathrm{R}=-0.36$; $\mathrm{p}<0.05)$ and LDL-cholesterol $(\mathrm{R}=-0.41 ; \mathrm{p}<0.05)$ and positive with HDL-cholesterol $(\mathrm{R}=0.45 ; \mathrm{p}<0.05)$.

The assessment of the relationship between omentin and anthropometric parameters as well as biochemical results demonstrated a negative correlation between omentin and insulin $(\mathrm{R}=-0.47 ; \mathrm{p}<0.01)$ and HOMA-IR $(\mathrm{R}=-0.43 ; \mathrm{p}<0.05)$. The results of the tests are shown in Table 4.

There was no statistically significant correlation for visfatin.

The correlation between adipokines and biochemical and anthropometric parameters and the degree of disability evaluated by the EDSS scale was also assessed, showing that EDSS correlated positively with BMI $(\mathrm{R}=0.36 ; \mathrm{p}<0.05)$ and negatively with HDL-cholesterol $(\mathrm{R}=-0.47 ; \mathrm{p}<0.01)$ (Tab. 5). 
Table 5. Correlation of Expanded Disability Status Scale (EDSS) in patients with multiple sclerosis (MS)

\begin{tabular}{lccc}
\hline Parameter A & Parameter $\mathbf{B}$ & $\mathbf{R}$ & $\mathbf{p}$ \\
\hline EDSS & BMI & 0.36 & $<0.05$ \\
\hline EDSS & HDL-cholesterol & -0.47 & $<0.01$ \\
\hline
\end{tabular}

$\mathrm{BMI}$ — body mass index; HDL — high-density lipoproteins

\section{Discussion}

Our study is the first in which a full spectrum of adiponectin was assessed in patients diagnosed with multiple sclerosis. We found no significant differences between adiponectin and the levels of its fractions when the MS group and the controls were compared. However, when the adjustment to BMI as a confounding factor was performed, marked differences were observed, with lower levels of total and HMW adiponectin and higher values of MMW adiponectin in MS. The significance of our findings is that changes in the adiponectin array may depend on factors other than BMI only.

Data in the literature concerning adiponectin concentration (without adjustment to BMI) in individuals suffering from multiple sclerosis are inconsistent.

In line with our non-adjusted to BMI results, Hietaharu et al. failed to find significant differences between adiponectin concentration in serum of MS patients and the controls, who, interestingly, were twins. Of note, the twins with MS had higher concentrations of adiponectin in CSF than their asymptomatic co-twins [28]. These findings suggest that peripheral secretion of adiponectin does not mirror the production in the central nervous system. As in our results, adiponectin in newly diagnosed MS patients did not vary in comparison with the healthy controls in the study by Penesova et al. [29].

Contrary to our findings, the group of Signoriello found that total adiponectin was markedly higher in patients with MS when compared with controls. Furthermore, the authors suggested that the adiponectin oligomerisation is altered in MS because they observed an increase in HMW oligomers. Notably, the results of longitudinal observation suggest that patients with MS with higher levels of adiponectin at baseline have a significantly higher risk of progression and severity [30]. Furthermore, the group of Palavra observed an increased adiponectin concentration in their group of individuals suffering from MS [31].

Düzel et al. also found higher adiponectin levels in MS than in the controls. Interestingly, there were differences in adiponectin concentration amongst MS patients with a different first clinical episode. As reported, serum adiponectin levels were found to be significantly lower in patients with optic neuritis in the first clinical episode than in other MS individuals, and the results in patients with optic neuritis were comparable to those of the controls [32].

Interestingly, Kraszula et al. in one study and Musabak et al. in another study reported that they independently observed in MS individuals a lower concentration of adiponectin than in the sera of controls $[33,34]$. However, it should be highlighted that both groups of patients were already treated for MS in the time of the study. Furthermore, results from Yousefian et al. showed a lower concentration of adiponectin in MS patients compared to the controls with concomitant differences in single nucleotide polymorphism of the adiponectin gene, which additionally was gender specific. Besides, adiponectin genotype was also associated with susceptibility to a specific type of MS, the primary progressive multiple sclerosis [35]. So far only a few authors have presented their results concerning adiponectin in MS after adjustment to BMI. Contrary to our data, Çoban et al. found higher total adiponectin concentration among MS individuals. These authors suggested the involvement of adiponectin as well as other adipokines in the pathogenesis and progression of MS [36]. It should also be noted that results from a prospective study by the group of Kvistad indicate that serum levels of adiponectin, also adjusted for $\mathrm{BMI}$, are not associated with multiple sclerosis disease activity or treatment response [37]. It is noteworthy that results of a Mendelian randomisation study suggested that lifelong exposure to a substantially (two-SD) genetically elevated adiponectin level has no clinically relevant effects on MS susceptibility in individuals of European descent [38].

The explanation for the adiponectin levels differences between published results may include influence on the results by sample size, age, race, the presence of metabolic alterations (e.g. diabetes), MS duration, MS type, and treatment.

An important role of adiponectin in MS has been confirmed in an experimental study by Piccio et al. The authors performed their study on adiponectin knock-out (ADPKO) mice with experimental autoimmune encephalomyelitis (EAE). ADPKO mice had a worse EAE course with higher central nervous system (CNS) inflammation, demyelination, and axonal injury than wild-type (WT) mice. In vitro measurement of proliferation and cytokine release from immunised ADPKO vs. WT mice in response to antigen revealed that pro-inflammatory cytokines (IFN $\gamma \mathrm{TNF} \alpha$, IL-17, and IL-6) were higher in ADPKO compared to WT mice. Furthermore, the spleen and central nervous system of ADPKO had fewer T regulatory cells (Tregs) than those of WT mice. Noticeably, globular adiponectin 
(gADP) administration in vivo ameliorated EAE and was associated with an increase in Tregs. These results confirm that adiponectin is a potent regulator of T-cell functions during EAE [39].

Another in vitro study by Zhang et al. also indicated that adiponectin deficiency promoted CNS inflammation and demyelination and exacerbated experimental EAE. Detailed data showed that adiponectin deficiency increased the Th1 and Th17 cell cytokines of both the peripheral immune system and CNS in mice suffering from EAE, and predominantly promoted the antigen-specific Th17 cells' response in autoimmune encephalomyelitis. These results suggest that adiponectin could inhibit Th17 cell-mediated autoimmune CNS inflammation [40].

In our MS group, we found significantly higher levels of visfatin when compared to the controls. However, the difference diminished after adjustment to BMI.

Our non-adjusted-to-BMI results are in concordance with the findings of Emamgholipour et al., who observed elevated visfatin levels in patients with MS. In addition, these authors found a positive correlation of visfatin with TNF $\alpha$, IL- $1 \beta$, and high-sensitivity $\mathrm{C}$-reaction protein (hs-CRP) in the group diagnosed with MS [41]. Moreover, in the study by Mirzaei et al. the levels of visfatin were also significantly higher in MS patients [42]. Both groups reported data that were not adjusted to BMI.

To our best knowledge, there is only one study in which omentin was assessed in individuals suffering from multiple sclerosis. The group of Assadi failed to find a significant difference in the levels of omentin after adjustment to BMI between MS subjects and their healthy counterparts [43]. Our results showed a marked difference when two groups were compared both before and after adjustment to BMI. We also observed in our MS group a negative correlation between omentin and insulin levels and the insulin resistance indicator HOMA-IR.

We are aware of the limitations of our study. Firstly, we could point out the relatively small sample size. However, we carefully selected study participants to achieve a homogenous group without the occurrence of metabolic disturbances, which included diabetes, hypertension, and dyslipidaemia in need of treatment. Also, our group of multiple sclerosis patients was unique due to an early and active phase of the disease, and because they were naïve to any treatment.

Secondly, we assessed only selected adipokines, but we chose those that were not yet well studied.

To conclude, our results indicate that adiponectin with its fractions, visfatin, and omentin cannot be considered as causative factors in the early phase of multiple sclerosis. However, based on our findings and data from other authors, a potential role of adipokines in MS is pos- sible because they might be involved in the pathogenesis of MS regarded as an autoimmune disorder.

\section{Author's contribution}

W.B. and J.K contributed equally to the manuscript.

\section{Funding}

The study was supported by the Centre of Medical Postgraduate Education Grant No. CMKP 501-1-31-22-18.

This research received no external funding.

\section{Conflicts of interest}

The authors declare no conflict of interest.

\section{References}

1. Dilokthornsakul P, Valuck RJ, Nair KV, et al. Multiple sclerosis prevalence in the United States commercially insured population. Neurology. 2016; 86(11): 1014-1021, doi: 10.1212/WNL.0000000000002469, indexed in Pubmed: 26888980.

2. Martin R, Sospedra M, Rosito M, et al. Current multiple sclerosis treatments have improved our understanding of MS autoimmune pathogenesis. Eur J Immunol. 2016; 46(9): 2078-2090, doi: 10.1002/eji.201646485, indexed in Pubmed: 27467894.

3. Guerrero-García Jd, Carrera-Quintanar L, López-Roa RI, et al. Multiple Sclerosis and Obesity: Possible Roles of Adipokines. Mediators Inflamm. 2016; 2016: 4036232, doi: 10.1155/2016/4036232, indexed in Pubmed: 27721574.

4. Thompson A, Baranzini S, Geurts J, et al. Multiple sclerosis. Lancet. 2018; 391(10130): 1622-1636, doi: 10.1016/s0140-6736(18)30481-1, indexed in Pubmed: 29576504 .

5. Gianfrancesco MA, Barcellos LF. Obesity and Multiple Sclerosis Susceptibility: A Review. J Neurol Neuromedicine. 2016; 1(7): 1-5, doi: 10.2924 5/2572.942x/2016/7.1064, indexed in Pubmed: 27990499.

6. Versini M, Jeandel PY, Rosenthal E, et al. Obesity in autoimmune diseases: not a passive bystander. Autoimmun Rev. 2014; 13(9): 981-1000, doi: 10.1016/j.autrev.2014.07.001, indexed in Pubmed: 25092612.

7. Dyaczyński M, Scanes CG, Koziec H, et al. Endocrine implications of obesity and bariatric surgery. Endokrynol Pol. 2018; 69(5): 574-597, doi: 10.5603/EP.2018.0059, indexed in Pubmed: 30379322.

8. Bilir BE, Güldiken S, Tunçbilek N, et al. The effects of fat distribution and some adipokines on insulin resistance. Endokrynol Pol. 2016; 67(3): 277-282, doi: 10.5603/EP.a2016.0023, indexed in Pubmed: 26884292.

9. Orlando A, Nava E, Giussani M, et al. Adiponectin and Cardiovascular Risk. From Pathophysiology to Clinic: Focus on Children and Adolescents. Int J Mol Sci. 2019; 20(13), doi: 10.3390/ijms20133228, indexed in Pubmed: 31262082

10. Shehzad A, Iqbal W, Shehzad O, et al. Adiponectin: regulation of its production and its role in human diseases. Hormones (Athens). 2012; 11(1): 8-20, doi: 10.1007/BF03401534, indexed in Pubmed: 22450341.

11. Liu M, Liu F. Regulation of adiponectin multimerization, signaling and function. Best Pract Res Clin Endocrinol Metab. 2014; 28(1): 25-31, doi: 10.1016/j.beem.2013.06.003, indexed in Pubmed: 24417943

12. Li P, Yang Li, Ma CL, et al. Low-molecular-weight adiponectin is more closely associated with disease activity of rheumatoid arthritis than other adiponectin multimeric forms. Clin Rheumatol. 2015; 34(6): 1025-1030, doi: 10.1007/s10067-015-2899-9, indexed in Pubmed: 25750183.

13. Achari AE, Jain SK. Adiponectin, a Therapeutic Target for Obesity, Diabetes, and Endothelial Dysfunction. Int J Mol Sci. 2017; 18(6), doi: 10.3390/ijms18061321, indexed in Pubmed: 28635626.

14. Ouchi N, Walsh K. A novel role for adiponectin in the regulation of inflammation. Arterioscler Thromb Vasc Biol. 2008; 28(7): 1219-1221, doi: 10.1161/ATVBAHA.108.165068, indexed in Pubmed: 18565846.

15. Yokota T, Oritani K, Takahashi I, et al. Adiponectin, a new member of the family of soluble defense collagens, negatively regulates the growth of myelomonocytic progenitors and the functions of macrophages. Blood. 2000; 96(5): 1723-1732, indexed in Pubmed: 10961870.

16. Makki K, Froguel P, Wolowczuk I. Adipose tissue in obesity-related inflammation and insulin resistance: cells, cytokines, and chemokines. ISRN Inflamm. 2013; 2013: 139239, doi: 10.1155/2013/139239, indexed in Pubmed: 24455420.

17. Neumeier M, Weigert J, Schäffler A, et al. Different effects of adiponectin isoforms in human monocytic cells. J Leukoc Biol. 2006; 79(4): 803-808, doi: 10.1189/jlb.0905521, indexed in Pubmed: 16434692. 
18. He $\mathrm{Y}, \mathrm{Lu} \mathrm{L}$, Wei $\mathrm{X}$, et al. The multimerization and secretion of adiponectin are regulated by TNF-alpha. Endocrine. 2016; 51(3): 456-468, doi: 10.1007/s12020-015-0741-4, indexed in Pubmed: 26407855.

19. Mayi TH, Duhem C, Copin C, et al. Visfatin is induced by peroxisome proliferator-activated receptor gamma in human macrophages. FEBS J 2010; 277(16): 3308-3320, doi: 10.1111/j.1742-4658.2010.07729.x, indexed in Pubmed: 20608974.

20. Xiao Ke, Zou WH, Yang Z, et al. The role of visfatin on the regulation of inflammation and apoptosis in the spleen of LPS-treated rats. Cell Tissue Res. 2015; 359(2): 605-618, doi: 10.1007/s00441-014-1997-3, indexed in Pubmed: 25358398.

21. Kumari B, Yadav UCS. Adipokine Visfatin's Role in Pathogenesis of Diabesity and Related Metabolic Derangements. Curr Mol Med. 2018; 18(2): 116-125, doi: 10.2174/1566524018666180705114131, indexed in Pubmed: 29974830.

22. Stofkova A. Resistin and visfatin: regulators of insulin sensitivity, inflammation and immunity. Endocr Regul. 2010; 44(1): 25-36, doi: 10.4149/endo 201001 25, indexed in Pubmed: 20151765

23. Yang RZ, Lee MJ, $\mathrm{Hu} \overline{\mathrm{H}}$, et al. Identification of omentin as a novel depot-specific adipokine in human adipose tissue: possible role in modulating insulin action. Am J Physiol Endocrinol Metab. 2006; 290(6): E1253-E1261, doi: 10.1152/ajpendo.00572.2004, indexed in Pubmed: 16531507.

24. Escoté X, Gómez-Zorita S, López-Yoldi M, et al. Role of Omentin, Vaspin, Cardiotrophin-1, TWEAK and NOV/CCN3 in Obesity and Diabetes Development. Int J Mol Sci. 2017; 18(8), doi: 10.3390/ijms18081770, indexed in Pubmed: 28809783

25. Watanabe T, Watanabe-Kominato K, Takahashi Y, et al. Adipose Tissue-Derived Omentin-1 Function and Regulation. Compr Physiol. 2017; 7(3): 765-781, doi: 10.1002/cphy.c160043, indexed in Pubmed: 28640441

26. Baranowska-Bik A, Kalisz M, Martyńska L, et al. Plasma adiponectin array in women with Alzheimer's disease. Endokrynol Pol. 2018; 69(5): 550-559, doi: 10.5603/EP.a2018.0055, indexed in Pubmed: 30117532.

27. Polman $\mathrm{CH}$, Reingold SC, Banwell B, et al. Diagnostic criteria for multiple sclerosis: 2010 revisions to the McDonald criteria. Ann Neurol. 2011 69(2): 292-302, doi: 10.1002/ana.22366, indexed in Pubmed: 21387374.

28. Hietaharju A, Kuusisto H, Nieminen R, et al. Elevated cerebrospinal fluid adiponectin and adipsin levels in patients with multiple sclerosis: a Finnish co-twin study. Eur J Neurol. 2010; 17(2): 332-334, doi: 10.111 1/j.1468-1331.2009.02701.x, indexed in Pubmed: 19538214.

29. Penesova A, Vlcek M, Imrich R, et al. Hyperinsulinemia in newly diagnosed patients with multiple sclerosis. Metab Brain Dis. 2015; 30(4): 895-901, doi: 10.1007/s11011-015-9665-1, indexed in Pubmed: 25809135.

30. Signoriello E, Lus G, Polito R, et al. Adiponectin profile at baseline is correlated to progression and severity of multiple sclerosis. Eur J Neurol. 2019, 26(2): 348-355, doi: 10.1111/ene.13822, indexed in Pubmed: 30300462.

31. Palavra F, Marado D, Mascarenhas-Melo F, et al. New markers of early cardiovascular risk in multiple sclerosis patients: oxidized-LDL correlates with clinical staging. Dis Markers. 2013; 34(5): 341-348, doi: 10.3233/DMA-130979, indexed in Pubmed: 23478275
32. Düzel B, Tamam Y, Çoban A, et al. Adipokines in Multiple Sclerosis Patients with and without Optic Neuritis as the First Clinical Presentation. Immunol Invest. 2019; 48(2): 190-197, doi: 10.1080/08820139.2018. 1528270, indexed in Pubmed: 30321074.

33. Kraszula L, Jasińska A, Eusebio MO, et al. Evaluation of the relationship between leptin, resistin, adiponectin and natural regulatory $\mathrm{T}$ cells in relapsing-remitting multiple sclerosis. Neurol Neurochir Pol. 2012; 46(1): 22-28, doi: 10.5114/ninp.2012.27211, indexed in Pubmed: 22426759.

34. Musabak U, Demirkaya S, Genç G, et al. Serum adiponectin, TNF- $\alpha$, IL-12p70, and IL-13 levels in multiple sclerosis and the effects of different therapy regimens. Neuroimmunomodulation. 2011; 18(1): 57-66, doi: 10.1159/000317393, indexed in Pubmed: 20714168.

35. Yousefian $M$, Nemati R, Daryabor G, et al Gender-Specific Association of Leptin and Adiponectin Genes With Multiple Sclerosis. Am J Med Sci. 2018; 356(2): 159-167, doi: 10.1016/j.amjms.2018.03.008, indexed in Pubmed: 30219158

36. Çoban A, Düzel B, Tüzün E, et al. Investigation of the prognostic value of adipokines in multiple sclerosis. Mult Scler Relat Disord. 2017; 15: 11-14, doi: 10.1016/j.msard.2017.04.006, indexed in Pubmed: 28641765 .

37. Kvistad SS, Myhr KM, Holmøy T, et al. Body mass index influence interferon-beta treatment response in multiple sclerosis. J Neuroimmunol. 2015; 288: 92-97, doi: 10.1016/j.jneuroim.2015.09.008, indexed in Pubmed: 26531700.

38. Devorak J, Mokry LE, Morris JA, et al. Large differences in adiponectin levels have no clear effect on multiple sclerosis risk: A Mendelian randomization study. Mult Scler. 2017; 23(11): 1461-1468, doi: 10.1177/1352458516681196, indexed in Pubmed: 27903934.

39. Piccio L, Cantoni C, Henderson JG, et al. Lack of adiponectin leads to increased lymphocyte activation and increased disease severity in a mouse model of multiple sclerosis. Eur J Immunol. 2013; 43(8): 2089-2100, doi: 10.1002/eji.201242836, indexed in Pubmed: 23640763.

40. Zhang K, Guo Y, Ge Z, et al. Adiponectin Suppresses T Helper 17 Cell Differentiation and Limits Autoimmune CNS Inflammation via the SIRT1/PPAR/ROR t Pathway. Mol Neurobiol. 2017; 54(7): 4908-4920, doi: 10.1007/s12035-016-0036-7, indexed in Pubmed: 27514756.

41. Emamgholipour S, Eshaghi SM, Hossein-nezhad A, et al. Adipocytokine profile, cytokine levels and foxp3 expression in multiple sclerosis: a possible link to susceptibility and clinical course of disease. PLoS One. 2013; 8(10): e76555, doi: 10.1371/journal.pone.0076555, indexed in Pubmed: 24098530.

42. Mirzaei K, Hossein-Nezhad A, Mokhtari F, et al. Visfatin/NAMPT/PBCEF and Cytokine Concentration in Multiple Sclerosis Patients Compared to Healthy Subjects. Eur J Inflamm. 2011; 9(1): 31-37, doi: 10.1177/172 $1727 \times 1100900105$

43. Assadi M, Salimipour H, Akbarzadeh S, et al. Correlation of circulating omentin-1 with bone mineral density in multiple sclerosis: the crosstalk between bone and adipose tissue. PLoS One. 2011; 6(9): e24240, doi: 10.1371/journal.pone.0024240, indexed in Pubmed: 21935388. 